\title{
McDonald's Performance and Brand Design in Chinese Market
}

\author{
Xiaoru Du ${ }^{1, a}$, Huilan Wei ${ }^{2, b}$ and Mengmeng Wang ${ }^{2, c}$ \\ ${ }^{1}$ School of Art and Design, Wuhan University of Technology, Wuhan 430070, China; \\ ${ }^{2}$ School of Art and Design, Wuhan University of Technology, Wuhan 430070, China; \\ a1518369288@qq.com, ${ }^{b} 391856484 @ q q . c o m,{ }^{c} 1010508295 @ q q . c o m$
}

Keywords: McDonald’s performance, brand design, Chinese market.

Abstract: McDonald's, as a quick service restaurant, it is the market leader in American fast food industry. Moreover, as a western fast food brand, it is also extremely successful in Chinese market. This report entered market to analyze its performance through the perception of brand in home market, and finds out that the Chinese consumer has a completely different perception from American consumers. Moreover, it will explore global marketing strategy of McDonald's, and find that McDonald's adapting standardization market strategy can improve their brand identity.

\section{Introduction}

As the increasing sharpness of economic globalization, there are a growing number of global brands has been entering the Chinese market. According to Davis (2000) reported that the western ideologies and Chinese traditional belief intricately interwoven in nowadays China, Chinese consumers have a significant changeable in consumption and consumerism. Moreover, Chinese consumer incoming has an increase, 40 million individuals are able to earn more than RMB 98,000 per year and Chinese market as is becoming most of multinational firms promising market (Ogba, 2011). Therefor, in todays China, there are lots of western companies appeared and success in Chinese market.

McDonald's is a leading brand in the fast food industry, and it is quite successful in Chinese market and popular by Chinese consumer. This report will analyze McDonald's global marketing strategy and discuss its performance in Chinese market; also this report will focus on perception of McDonald's brand in Chinese market and compare it with American market.

\subsection{Industry overview}

McDonald's as a quick service restaurant, it is the market leader in American fast food industry (Young and Page, 2014). Moreover, as a western fast food brand, it is also extremely successful in Chinese market. The Chinese fast food industry has a significant growth, the revenues of this industry reached about 35 billion dollars in 2006 and increased 27.2 percent than last year (Datamonitor, 2007). Moreover since Chinese market reform in 1979, the fast food industry is becoming the one of 
the top 7 fastest increasing industry in China (Anderson and He, 1999).

And as a western eating habit is attracting a large number of consumer interests, it will be able to save more time and money compare with Chinese food. Compare with domestic fast food, western fast foods are more popular in Chinese market and has a long history in china begun in 1987. Shen and Xiao (2014) claimed that even the Chinese local fast food has a quickly increase, the completion between western and local fast food are still weak and western fast food far ahead for Chinese domestic fast food. Additionally, the quickly economic increasing and fast-paces lifestyle lead average Chinese consumers are more pay attention to time-saving services than products' taste and quality. In recent years, there is a growth of western fast food brand has been entering Chinese market, such as: McDonald's, KFC, Burger King, Pizza hut and et al. KFC is the fist western fast food brand to access Chinese market and had more than 38,000 locations in China over 100 cities, and it has 1.3 percent market share compare McDonald's 0.7 percent market share and acquire the market lead in Chinese fast food industry (Qin et al., 2010). And KFC is also the biggest competitor and market challenge of McDonald's in China, other competitors, like Burger King, Pizza hut and Subway are all its market followers.

\subsection{Brand overview}

McDonald's is the well-know American fast food chain in the world and it established in1955. As a famous global brand, McDonald's had 36,258 restaurants located 119 different countries around the world at year-end 2014, and it generated \$ 1.2 trillion in annual sales in 2013(McDonald's Annual Report 2014). Compare with KFC adaption strategy, McDonald's adopt worldwide-standardized strategy, and entered Chinese market in 1990 by opening first restaurant in Shenzhen. Moreover, Qin et al. (2010) reported that McDonald's has about 800 restaurants in 2007 and hope to expend almost 900 restaurants in 2008 in Chinese market. Even though the McDonald's faced intense competition market, it still has a growing market share and successful in Chinese market.

\section{Literature review of brand design}

McDonald's as a successful global brand not only has a high brand identity and visual identity in China but also throughout around the world. Belen et al. (2001) argued that the strong brand depends on the consumer satisfaction and purchase intention. The McDonald's adapt standardized marketing strategy, which will enhance their brand identity around the world. Lee and Shavitt (2009) reported that McDonald's brand has a highly identity and perception of brand in Chinese market, it means the majority of consumers are able to understand this brand.

\subsection{Visual identity}

In the recent years, the intense competitive and modern market leading the brand communication are more focus on the visual design (Salzer-Morling and Lars, 2004). Compare with other brand factors (products and service quaility), the brand visual is the faster approaches impresses the brand by the consumers and improve the perception of brand among consumers (Phillips et al., 2014). Visual indentity as a symbol of the corporation and brand, it is contain a lot of information about the brand. Van Riel and Van den Ban (2001) claimed that visual identity consists of the name of company, visual logo, trademark, symbol of color and several graphical elements, it is able to represent the characteristics of the corporation and brand.

McDonald's has a highly identity of brand visual, the golden arches are a powerful symbol logo of McDonald's. Van den Bosch et al. (2005) expressed that the golden arches logo of McDonald's is a 
quite strong guidance for individuals to turn off the next exit and eat at the restaurant in the highway. It means McDonald's visual identity is extremely successful and has a deeply impressive. The successful visual identity can bring lots of profits and reputations for the brand. This view proved by Leitch (1999), the identifiable logos of McDonald's, Coke, Sony, IBM, and Nike contribute billions of dollars of revenues to their company. Therefor, improving the brand visual identity is quite necessary for a global brand, it will bring lots of profits and value for their brand and help them success in the new market. Especially in Chinese market, the brand visual identity investment is vital activities for attracting Chinese consumers, the logo of western brand represents quality and safety and majority of Chinese consumers had highly brand awareness (Ogba and Tan, 2011).

\subsection{Brand image}

Herzog (1963) explained that brand image is the consumers' perception of brand and represented the image of brand in consumer memory depending on consumers. The brand image directly reflects company failed or success, and reveals consumers awareness of this brand. Biel, A.L. (1993) expressed that the brand image are consist of three elements, such as: the image of provider of the product/service or corporation image; the image of the user; the image of the product/service itself. Moreover, brand image also can influence the consumer satisfaction and loyalty Fornell et al. (2006). The products quality and service all are able to improve the brand image and enhance positive perception of the brand (Hart and Rosenberger 2004). Therefore, in order to enhance the brand identity and consumer loyalty, the brand need to pay more attention to stronger products personality and service quality by impressed consumer memories.

\section{New market perceptions of the brand}

The perception of the brand is important for companies' performance, it is directly impact on consumers purchase behavior. And in the different market, the consumers have the various perceptions of the brand. McDonald's as a well-know global brand, its restaurants located around the world, the consumer in Chinese and American influenced by different environmental and cultural elements have the different perceptions.

US as McDonald's home market, the biggest reason about American consumers chooses it because of time saving and convenient. Harris (1990) reported that time of day, time spent eating and price are the three most key reasons for them to decide eating in which fast food restaurants. So the most of American consumers choose McDonald's depends on saving time and lower price. Moreover, the majority of McDonald's restaurants located in the exit of highway and setting lots of window for drivers to collecting food in the car, because that individuals in American all had a car for transport. Thus, in terms of the accessible location and fast service, American consumers are more prefer it. However, this situation are different in China, all the McDonald's restaurants are located the city center and large population places. Furthermore, the consumer in American are all considered that McDonald's produced the junk food and unhealthy, the senior citizens are all do not like it (). According to Maxwell (1992) expressed that there are 8 percent of US adults are fast food primary consumers because of their fast-paced lifestyle. As the results, US consumer think McDonald's is unhealthy for individuals, they choose it just by fast service and accessible facilities.

For Chinese market, there are some completely different factors for choosing McDonald's. Firstly, in contrast to US consumer holding McDonald's is unhealthy and junk food, Chinese consumer are more trust and prefer that American fast food brand--- McDonald's. Today, China local food industry are faced a big deal with food safety and security issue, such as: melamine in children' milk and illegally recycled waste cooking oil in local fast food restaurants (China daily, 2012). And 
McDonald's pay more attention to hygienic food and clean restaurant environmental, so Chinese consumers are more trust it and regard McDonald's as healthy and safety food. In another hand, McDonald's is a novel brands for Chinese consumers compare with domestic fast food brand, it will attract more consumer interests. And Lu (1994) reported that even McDonald's has a high-fat, the younger are still like it because of novelty and most of them are prefer to chat with friends and listen to music in McDonald's. Compare McDonald's are surrounded by parking lot in USA and focus on drive-through and take away options, it located in city center and served for chatting place in china. Furthermore, McDonald's are faced family and younger consumer segments in China. There are larges number of children's entertainment facilities in Chinese McDonald's restaurants, attracting lots of children play with friends in there. Compare with American elderly individuals, Chinese senior citizens are tend to go to McDonald's with their grandson and granddaughter. Due to the fast-pace lifestyle, grandparents had more time to bring up their grandchild instead of children's parents. So they tend to come with their grandchild to McDonald's and playing and eating in there.

\section{Global marketing strategy}

For the global brand, marketing strategy is the key factor for entering the new market and acquire successful. McDonald's as a famous global brand, it is good at standardized marketing strategy. The standardized marketing strategy focus on finding the homogeneous of demand world wide, it will be able to help company saving more resources and create high quality products (Viswanathan and Dickson, 2007). And McDonald's adapt standardized marketing strategy to access Chinese market and gain a highly brand identity with lowing cost.

Additionally, when the global brand entering a new market, the fist important factor is decide the segmenting, targeting and positioning of the market. This three marketing strategy will guide the company to adjust their management plan and promote company development (Geissler, 2001). McDonald's doing several market research before they entering Chinese market, they divided Chinese consumers into different part in terms of age level and type, such as: younger and family segments. Before 2003, McDonald's determined the family and children as their target market and primary consumers. However, in order to share the Chinese market with their competitors, it changed their target market to younger with 4---30 years old consumers in 2004 (Zhou and Zhang, 2012). And McDonald's played some Chinese pop music in their restaurants, just for attracting their primary consumer and competing with its competitors in China.

Even though McDonald's adapt standardization market strategy, it still adjusts several products taste in China under highly competitive market environment. Actually when the beginning of McDonald's access Chinese market, it still maintained standardization market strategy in their products and considered that just keep American style can distinct from Chinese fast food restaurants (Bian, 2009). However, facing the biggest challenge of KFC, they adjust their strategy and add some Chinese taste food into their menu, such as: fried egg, Chinese pancake and honey and ginger drink. Additionally, people are more prefer chicken and pork than beef influenced by Chinese diet habits, McDonald's add a large number of chicken offers instead of beef (Anderson and He, 1999). Furthermore, in order to improve the characteristics of their products and attract their primary consumer, McDonald's offered various gifts with their menu. Different with KFC toy provide with Children menu, McDonald's free gifts are offered to a wildly range of consumer's age. And younger consumers collect the majority of their free gifts, such as: rainbow cola cups of 6 colors (Zhou and Zhang, 2012). Moreover, as a global market strategy of products, the little changes of products to meet local culture also using in other foreign market. Such as McDonald's never provide pork in Muslims countries and beef hamburger in Hindus, McDonald's tried to respect and satisfied their entered market. 


\section{Branding and advertising issue}

With the highly competitive market, building a strong brand is becoming more difficult. The important factor for improve brand identity is build a strong bridge between brand and consumer, advertising is the faster and more convenient way to communicate with consumers (Kohli et al., 2005). McDonald's advertising is extremely perform well in US market, but compare with its biggest competitors (KFC) is not quite meet Chinese consumers' interest in Chinese market. McDonald's and KFC have the same consumer segments (family and younger), KFC advertising are more pay attention to family emotion and relationship with family members. In china, family member relationship and their emotions are rooted in traditional Chinese culture and family takes a large part of individual daily life. However, McDonald's did not integrate this Chinese culture into their advertising, it still maintain the American culture in advertising like joy and freedom. In other hand, McDonald's advertising style is not meet Chinese consumers ability of thinking. In the advertising, McDonald's did not directly express the product itself, it tends to express a new lifestyle and American think model to Chinese consumers. The biggest reason of McDonald's are not good at integrating Chinese culture into their advertising, it is McDonald's adapt standardization market strategy as their major approaches to enter new market and they spent few funds on research and development local consumer needs.

\section{Performance in new market}

McDonald's is the market leader in USA, but it lost market leader position in Chinese market. Even it still success in China, KFC are instead of its market leader position and gain the biggest market share. The reason why KFC can instead of McDonald's as the market leader because of their different global market strategies. McDonald's as a successful global brand, it focuses on global and adept standardization market strategy. However, KFC pay more attention to the local culture and localization, using adaptation market strategy. So KFC provide more products choice for Chinese consumers and more popular in Chinese market. Even McDonald's had some adjust and localization in Chinese market, it just has few Chinese taste products compare with KFC products menu. Moreover, McDonald's leader said they tend to maintain the American diet habits and provide standard product to attract consumers in China. But they ignore that KFC also as an American fast food restaurant, it not only contain traditional American food but also offered some Chinese taste food. So it more popular in Chinese market, and it more satisfied Chinese consumer needs. Another reason about McDonald's lost market leader, it is KFC is the first western fast food brand has been entered in Chinese market and has a long history in China. The majority of consumers are more understanding KFC than McDonald's, KFC has a highly brand loyalty in China.

\section{Conclusion}

McDonald's as a well-known global brand, it still success in China. This essay through the perception of brand in home market and entered market to analyze it performance, the Chinese consumer has a completely different perception from American consumers. Firstly, consumer considered that McDonald's is a safety and clean food in China, but American consumers thought it junk food and unhealthy food. Secondly, US consumer choose it because saving time, fast service and accessible facilities for drivers, Chinese consumer tend to use the restaurant as a chatting place and play in there. Finally, compare with USA, more elderly individuals are willing to go to McDonald's. Moreover, this report also explored global marketing strategy of McDonald's, and found that McDonald's adapting standardization market strategy to improve their brand identity. Even the 
McDonald's adapting standardization market strategy, it also adjust few products to meet Chinese consumers needs. Furthermore, the report also finds some branding and advertising issues in Chinese market and explained McDonald's did not integrate Chinese culture into their advertising. In conclusion, McDonald's is quite successful in USA but it lost their market leader in Chinese market, because that McDonald's focus global and has not enough activities to meet Chinese consumers needs. If McDonald's would like to get market leader, the only way for them is making their products and service more local and brand localization in Chinese market.

\section{References}

[1] Anderson, P.M. and He, X. (1999) Culture and the fast-food Marketing mix in people republic of china and the USA, Journal of international consumer marketing, 11(1), 77-95.

[2] Belen, A., Vazquez, R. and Iglesias, V. (2001) The effects of brand associations on consumer response, Journal of Consumer Marketing, 18(5), 410 - 425.

[3] Bian J. (2009). KFC's evolution in China. China Citic Press.

[4] China daily (2013) fast food industry report, [Online] Available from: http://fashion.chinadaily.com.cn/node_1127741.htm [Accessed:10/05/2015]

[5] Davis, D. (2000) The Consumer Revolution in Urban China. Berkeley, CA: University of California Press.

[6] Datamonitor (2007), Chinese Markets for Fast Food, Global Information, Inc., Asia Market Information \& Development Company, Farmington, CT.

[7] Fornell, C., Mithas, S., Morgeson, F.V. and Krishnan, M.S. (2006) Customer satisfaction and stock prices: high returns, low risk, Journal of Marketing, 70, 3-14.

[8] Lu, H. (1994) China's Great Gastronomical Revolution, China Today, 15(17), , 50-51.

[9] Harris, J. (1990) I Don't Want Food, I Want Fast, Forbes, 146 (Oct. 1), 186.

[10] Kohli, C.S., Harich, K.R. and Leuthesser, L. (2005) Creating brand identity: a study of evaluation of new brand names. Journal of Business Research, 58(11), 1506-1515.

[11] Lee, K. and Shavitt, S. (2009) Can McDonald's Food Ever Be Considered Healthful? Metacognitive Experiences Affect the Perceived Understanding of a Brand[J]. Journal of Marketing Research, 46(2), 222-233.

[12] Leitch, S. (1999) From logo-centrism to corporate branding? The (r)evolution in organisational identity, Australian Journal of Communication, 26 (3), 1-8.

[13] McDonald's (2014) McDonald's Annual Report [Online] Available from: http://www.aboutmcdonalds.com/content/dam/AboutMcDonalds/Investors/McDonald's\%202014\%20Annual\%20Report .PDF. [Accessed:10/05/2015]

[14] Ogba, I.E. and Tan,Z. (2011)Exploring the impact of brand image on customer loyalty and commitment in China, Journal of Technology Management in China, 4 (2), 132 - 144.

[15] Phillips, B.J., McQuarrie, E.F. and Griffin, W.G. (2014) The Face of the Brand: How Art Directors Understand Visual Brand Identity, Journal of Advertising, 43(4), 318-332.

[16] Qin, H., Prybutok, V. R. and Zhao, Q. (2010) Perceived service quality in fast-food restaurants: empirical evidence from China, International Journal of Quality \& Reliability Management, 27(4), 424 - 437.

[17] Salzer-Morling, M. and Lars, S. (2004) Silence of the Brands, European Journal of Marketing, 38 (1/2), 224-38.

[18] Shen, Q. and Xiao, P. (2014) McDonald's and KFC in China: Competitors or Companions?. Marketing Science 33(2), 287-307.

[19] Van den Bosch, A.L.M., De Jong, M.D.T. and Elving, W.J.L. (2005) How corporate visual identity supports reputation. Corporate Communications: An International Journal, 10(2), 108-116.

[20] Van Riel, C.B.M. and Van den Ban, A. (2001) The added value of corporate logos: an empirical study, European Journal of Marketing, 35 (3/4), 428-40.

[21] Viswanathan, N.K. andDickson, P.R.(2007) The fundamentals of standardizing global marketing strategy, International Marketing Review, 24(1), 46 - 63.

[22] Zhou, L. and Zhang, Q. (2012) Cultural adaptation pattern analysis of McDonald's and KFC in the Chinese market, Uppsala University Department of Business Studies Master Thesis.

[23] Young, C. and Page, A. (2014) A Model for Predicting Advertising Quality As a Key to Driving Sales Growth How Television Advertising Quality Affected McDonald's Sales Growth Over Six Years, Journal of advertising research, 54(4), 393-397. 